\title{
Structural improvement of a bio-inspired 3D globular carbon foam by a continuously thermal treatment: A comprehensive study
}

\author{
J Marx*, H Beisch, S Garlof and B Fiedler \\ Institute of Polymer Composites, Hamburg University of Technology, Denickstr. 15, 21073 Hamburg, Germany
}

\begin{abstract}
The manufacturing of a 3D interconnected globular carbon foam, called Globugraphite, is based on the replication of the zinc oxide ( $\mathrm{ZnO}$ ) template morphology by carbon with simultaneous removing of the template material in the chemical vapour deposition (CVD - replica CVD (rCVD)) process. The growth mechanism of the presented carbon foam affected the formation of defects at the atomic level which leads in the following to graphitic pieces instead of layers. This substructure influences properties, such as electrical conductivity of the carbon foam negatively. By undergoing a temperature treatment at $1600^{\circ} \mathrm{C}, 1800^{\circ} \mathrm{C}, 2000^{\circ} \mathrm{C}$ and $2200^{\circ} \mathrm{C}$ in a protective gas atmosphere the carbon structure heals at the atomic level. The connection of the $\mathrm{sp}^{2} / \mathrm{sp}^{3} \mathrm{graphitic} \mathrm{pieces}$ to graphitic $\mathrm{sp}^{2}$ layers due to the thermal annealing is analysed via transmission electron microscopy (TEM) observation and Raman spectroscopy. Based on these analysis methods a model of the graphitization progress is created which explains the clearly increase of the electrical conductivity and the oxidation temperature.
\end{abstract}

\section{Introduction}

Since the discovery of carbon nanostructures such as carbon nanotubes (CNTs) [1] and graphene [2] the interest increases to use such materials for several applications, e.g. sensors [3], bioimplantats [4], composites [5-7] and batteries [8]. The development of 3D carbon structures is the next step to generate more applications with improved or specially designed properties. A variety of manufacturing methods opens a new field of research. Manufacturing processes can be distinguished between a template-based [9-11] and a templatefree [12] methods for the direct production of carbon aerogels. In addition, assembly of graphitic structures [13-16] can be carried out. One of these methods was the discovery of Aerographite [11]. Based on a $\mathrm{ZnO}$ template with tetrapodal morphology, a carbon foam is synthesized in a one-step CVD process by reduction of $\mathrm{ZnO}$ in gaseous zinc (Zn) in combination of epitaxy and catalytic graphitization [17]. The unique properties of this $3 \mathrm{D}$ interconnected carbon foams, leads to vary applications, such as supercapacitors $[18,19]$, and basic structure for the growth of nerve cells or sensors [20,21]. The growth process of carbon nanostructures leads to the formation of defective points at the atomic level during the arrangement of carbon atoms. These defects reduce the mechanical $[22,23]$ as well as the electrical [24] properties of carbon structures. The high temperature annealing of carbon structures especially of carbon nanotubes is a powerful tool to heal structural defects [25]. Several groups investigated the influence of the annealing on the morphology and improvement of properties of CNTs [26] or Graphene [27]. It was shown that with increasing temperature, the electrical resistance decreases and the oxidation temperature increases at the same time $[22,26]$. In addition, to high-temperature graphitization, first annealing processes with graphene could also be observed at a temperature of up to $600^{\circ} \mathrm{C}$ [27]. Furthermore, several groups showed that a temperature treatment of carbon structures results in a reorientation of the graphitic layers. Raman spectroscopy is an effective technique of measuring this structural change [25,26,28,29]. However, there are no comprehensive studies on the graphitization process and the influence of temperature. In addition, the morphology and morphology change in carbon foams with regard to the healing process is expected to lead to other mechanisms that need to be clarified.

In the present work, we show for the first time the effect of high temperature annealing as a function of the treatment temperature on the electrical and morphological properties of 3D carbon structures, called Globugraphite. The manufacturing of these structures based on, as described in previously works, the synthesis of Aerographite [11,17]. To heal the structure of Globugraphite at atomic level and analyze the influence of the treatment temperature, the carbon foam were heattreated at $1600^{\circ} \mathrm{C}, 1800^{\circ} \mathrm{C}, 2000^{\circ} \mathrm{C}$ and $2200^{\circ} \mathrm{C}$ for 2 hours in an inert argon atmosphere. The healing process of the graphitic layers is analyzed via Transmission electron microscopy and Raman spectroscopy. Furthermore, we examine the extent to which graphitization influences temperature stability and the electrical conductivity. Based on the analytical techniques a model of the graphitization progress in the presented 3D carbon structures is created.

\section{Materials and methods}

\section{Manufacturing of hierarchical ceramic templates}

The manufacturing of these carbon structures is based on a twostep process, as previously reported in more details [19]. The replication process of the template morphology takes place in the rCVD method, as previously for the reported for Aerographite [11,17]. In the first process step, a porous ceramic is produced via mixing $\mathrm{ZnO}$ powder (Sigma Aldrich, ReagentPlus, purity of $99.9 \%, 5 \mu \mathrm{m}$ ) with a polymer

Correspondence to: J Marx, Institute of Polymer Composites, Hamburg University of Technology, Denickstr. 15, 21073 Hamburg, Germany, Tel: +49 (0)40/42878 2565; E-mail: janik.marx@tuhh.de

Key words: replica CVD process, thermal graphitization, Raman spectroscopy, TEM, electrical conductivity

Received: September 24, 2017; Accepted: November 06, 2017; Published: November 09, 2017 
binder (Polyvinyl Butyral-PVB, Mowital, B60 HH, Kuraray,, purity: 99.5\%). After the sample form has been prepared via the uniaxial press, the sintering of the green body takes place, with a defined sintering temperature at $400^{\circ} \mathrm{C}$, so that only the sinter necks are formed. This results in a porous hierarchical structure.

\section{Synthesis of hierarchical carbon foam}

In the second process step the replication of the template structure takes place in the rCVD process. The CVD reactor (Carbolite HZS 12/1900) is heated up to $760^{\circ} \mathrm{C}$, a gas stream being set with the process gases argon $(0.2 \mathrm{l} / \mathrm{min})$ and hydrogen $(60 \mathrm{ml} / \mathrm{min})$. The precursor (toluene, Alfa Aesar, 99.5\%) is injected into the preheated zone with an injection rate of $5 \mathrm{ml} / \mathrm{h}$. After a toluene injection time of 60 minutes, the temperature is increased to $900^{\circ} \mathrm{C}$ for 60 minutes, without the injection of the carbon source. The process ends with cooling down without a supply of hydrogen and with an argon flow of $0.41 / \mathrm{min}$. The prepared samples have a cylindrical geometry with a diameter of $11.75 \pm 0.31$ $\mathrm{mm}$ and a height of $1.33 \pm 0.05 \mathrm{~mm}$.

\section{Analysis methods}

The graphitization was carried out in high-temperature furnaces (Gasdrucksinterofen, Dieckmann and Gero HTK 8) for 2 hours in an argon protective atmosphere at $1600^{\circ} \mathrm{C}, 1800^{\circ} \mathrm{C}, 2000^{\circ} \mathrm{C}$ and $2200^{\circ} \mathrm{C}$. Before the furnace was heated up to the appropriate temperature, the furnace was repeatedly evacuated and purged with argon. The final pressure in the furnace was about 100 mbar. The samples were heated up and cooled down with $20 \mathrm{~K} / \mathrm{min}$.

The morphology was characterized via scanning electron (SEM; Zeiss Supra VP 55, $5 \mathrm{kV}$ acceleration voltage) and the influence on the formation of the graphitic layers by using the transmission electron microscope (FEI Talos F200X, 200kV acceleration voltage). The samples for the TEM observations were prepared in accordance with the sample preparation as described previously in [19]. The samples were dispersed via the ultrasonic sonotrode (Bandelin Sonoplus) in methanol (LC-MS, $>99.9 \%$, Sigma Aldrich), with $30-45 \%$ of the maximum power for $30-45$ seconds. Followed by this the solution was dropped onto a TEM grid and dried at $80^{\circ} \mathrm{C}$ for 45 minutes on a heating plate. Furthermore, the graphitization progress is analyzed by using Raman spectroscopy (HORIBA Jobin Yvon HR 800, wavelength: 632 $\mathrm{nm})$. The Raman spectra were obtained at room temperature with a spectral width of $500-3000 \mathrm{~cm}^{-1}$ and an acquisition time of 10 seconds at several positions. The $\mathrm{I}_{\mathrm{D}} / \mathrm{I}_{\mathrm{G}}$ or $\mathrm{D} / \mathrm{G}$ ratio ratio are calculated based on the peak maxima of the fitted curves (Lorentz Fit). Moreover, the grapitization is analysed by measuring the specific surface area (SSA) via the Brunauer- Emmett -Theory (BET) method (AUTOSORB。iQ, Hersteller Quantachrome Instruments ). The SSA is calculated based on the quenched solid density functional theory (QSDFT). Additionally, the oxidation temperature was investigated by using the thermogravimetric analysis (TGA, TA instruments Q900 TGA). The samples were heated up to $900^{\circ} \mathrm{C}$ with a heating and cooling rate of $20 \mathrm{~K} / \mathrm{min}$ in a synthetic air ( $20 \mathrm{vol} \%$ oxygen) atmosphere. Finally, the electrical conductivity is measured at room temperature by using a four-wire configuration with a defined current at the source meter of $1 \mathrm{~mA}$ (Keithley 2602 System SourceMeter). The electrical conductivity $\sigma$ is calculated according to equation (2) by using the measured geometry via equation (1).

$$
\begin{gathered}
A=\pi \cdot \frac{d^{2}}{4} \\
\sigma=\frac{h}{R \cdot A}
\end{gathered}
$$

Where,

$$
\begin{aligned}
& \text { A }=\text { sample surface }\left(\mathrm{m}^{2}\right) \mathrm{d}=\text { sample diameter }(\mathrm{m}) \mathrm{h}=\text { sample height }(\mathrm{m}) \\
& \mathrm{R}=\text { electrical resistance }(\Omega) \\
& \sigma=\text { electrical conductivity }(\mathrm{S} / \mathrm{m})
\end{aligned}
$$

\section{Results and Discussion}

The produced ceramic templates has an hierarchical structure with macro pores of approximately 2-10 $\mu \mathrm{m}$, meso pores between the carbon shells with a width of less than $50 \mathrm{~nm}$, as can been see in Figure 1a. Figure $1 \mathrm{~b}$ shows the formation of sintering necks between the $\mathrm{ZnO}$ particles due to a specially set sintering process. This is resulting in a highly porous structure with a high specific surface area as previosly reported [19]. The macro pores are formed by burning out the binder in the sintering process. The meso pores are formed by a specific adjustment of the sintering temperature, so that a further diffusion is prevented and thus a complete sintering is avoided. By replicating the template morphology into a carbon structure via the rCVD process, the ceramic structure is replaced by a few nanometer thick carbon shell as shown in Figure $1 \mathrm{c}$-d. This structure has the same globular morphology as the $\mathrm{ZnO}$ template, as shown in Figure $1 \mathrm{~b}$-d. The hierarchical structure consisting of several planes of pore-like structures, such highly specific surfaces, as Figure 1c shows. Furthermore, the carbon shells are connected via the previously formed sintering necks (Figure 1d). It should be mentioned that the morphology of Globugraphite is not changed by the graphitization during the thermal annealing process.

To understand the graphitization of carbon structures it is important to analyze the influence of treatment method on the atomic arrangement of the graphitic layers. Untreated Globugraphite is consisting of short graphitic pieces with gaps or micro pores of about a nanometer, as Figure 2a shows. This atomic structure is based on the growth mechanism of such structures. As growth process always causes defects in carbon structure these affect the properties of these structures. As already shown for the tetrapodal carbon foam, which are also produced based on a $\mathrm{ZnO}$ template, a catalytic graphitization is carried out during the synthesis of the structures. This leads to the diffusion of the catalyst $(\mathrm{Zn})$ through the graphitic layers which cannot completely closed. This has an influence on the formation of the defect density [17], which can be analyzed by means of Raman spectroscopy. By annealing of the carbon foam, a reorientation and further a connection of the individual graphitic pieces with increasing of the annealing temperature to graphitic layers is observed, as shown in Figure $2 b-e$.

Raman spectroscopy is a standardized technique to analyze the influence of structural properties or modifications such as healing processes by thermal treatments. The results from the Raman spectroscopy fits well with the previously observed TEM imgaes. As can be seen in Figure 3a, the Raman spectra of the untreated sample shows two peaks, one at $\sim 1330 \mathrm{~cm}^{-1}$, called the D-peak and a second peak at $\sim 1580 \mathrm{~cm}^{-1}$, the G-peak [30-32]. As reported for Aerographite, this carbon foams is consits of $\mathrm{sp}^{2}$ and $\mathrm{sp}^{3}$ carbon [11], which should be the same behaviour for the presented carbon structure. By calculating a ratio from both peaks, an intensity factor called $\mathrm{D} / \mathrm{G}$ ratio or $\mathrm{I}_{\mathrm{D}} / \mathrm{I}_{\mathrm{G}}$ ratio can be determined. The untreated sample has an R-value of more than 1. This means that the structures produced have a high defect density. For tetrapodal carbon structures, which are also produced based on a $\mathrm{ZnO}$ template, the $\mathrm{R}$ value is also higher than 1, which is confirmed by previously works $[17,33,34]$. This is due to the growth mechanism in which zinc is used as the catalyst for the arrangement of the graphitic 

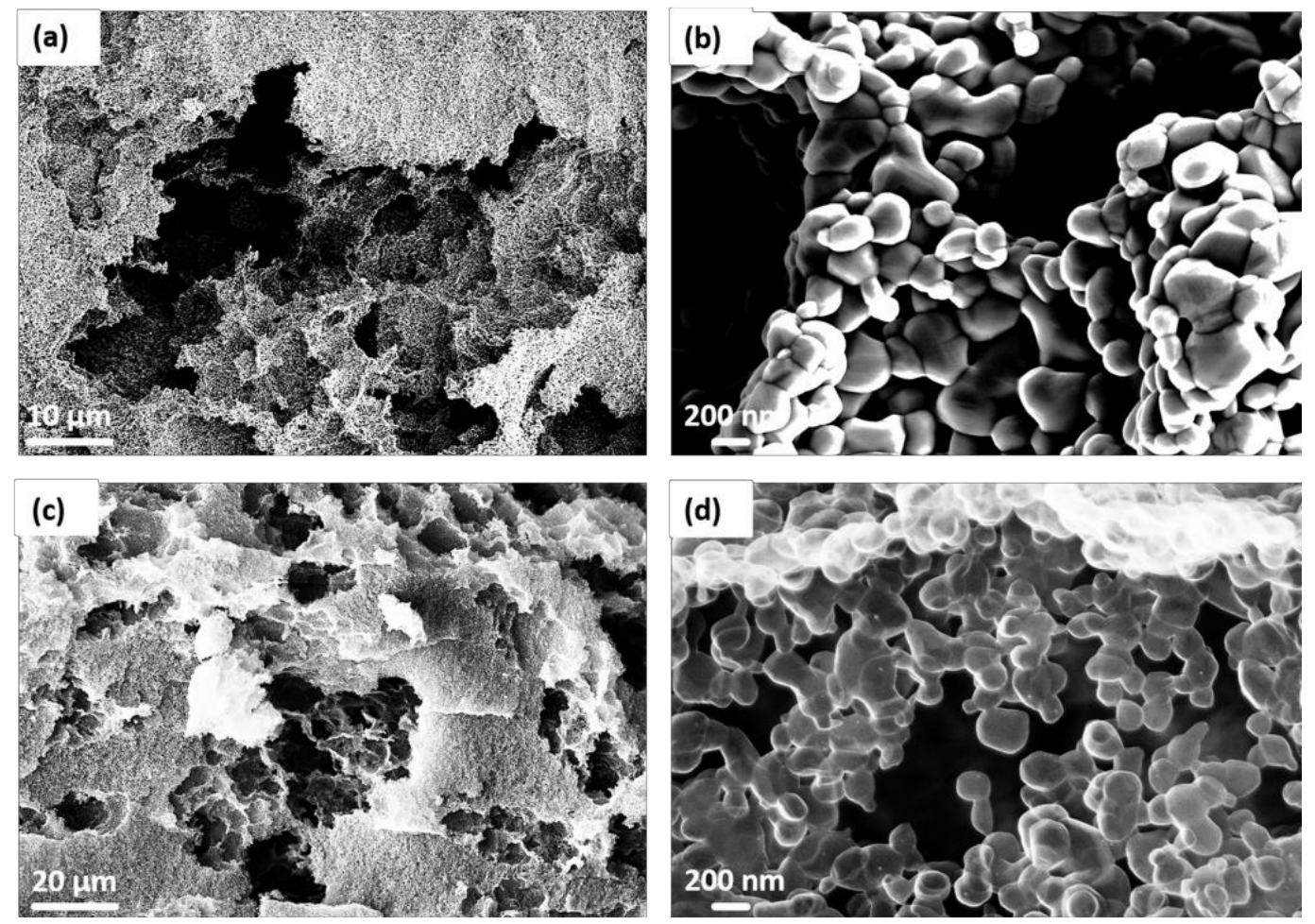

Figure 1. SEM image of the porous hierarchical ceramic structure after the sintering process (a) with its magnified area (b) and of the replicated carbon structure after the CVD process (c) with is magnified area $(\mathrm{d})$.

pieces. The diffusionn of zinc, some by-products through the carbon wall and the catalysis leads to the formation of gaps between the formed pieces [17]. Here, untreated Globugraphite do not have a G'-band or 2D-band called $\left(\sim 2660 \mathrm{~cm}^{-1}\right)$. The appearance of strong second order peaks indicates that the tubes have a higher order in their structure, similar the structure of graphite [35].

At first with increasing of the treatment temperature at $1600^{\circ} \mathrm{C}$ and $1800^{\circ} \mathrm{C}$ the $\mathrm{D} / \mathrm{G}$ ratio increase continuously and reaches a maximum at 1.664 , as shown in Figure 3b. The increase in the defect density can be explained by the diffusion and reorientation of carbon atoms and the simultaneously formation of defects in the formed $\mathrm{sp}^{2}$ lattices. The $\mathrm{D}^{\prime}$ peak describes and confirms the assumtion of the defects in $\mathrm{sp}^{2}$ lattices [32]. Furthermore, the ratio of G-band to $\mathrm{D}^{\prime}$-band decrease with increasing temperatures, which indicates a reduction of lattices defectes in the carbon layers. Besides, the splitting of the G-band into the $\mathrm{D}^{\prime}$ band, as already detected in other high temperature annealing processes by several groups $[28,29]$. This splitting is based on a transformation into a graphitic structure and the formation of defects in the formed $\mathrm{sp}^{2}$ layers. Wehreas, the $\mathrm{G}^{\prime}$-peak describes the three-dimensional order of the graphitic $\mathrm{sp}^{2}$ layers [25]. Behler et al. (2006) interpreted the shift of the $\mathrm{G}$ peak to $\sim 1581 \mathrm{~cm}^{-1}$ during the graphitization process with the increasing graphitic arrangement of the carbon lattices in MWCNTs, which correlates with the theoretical position in graphite [28]. This shift from $\sim 1585 \mathrm{~cm}^{-1}$ to $\sim 1581 \mathrm{~cm}^{-1}$ of the G-peak also occurs during the thermal treatment in the here presented carbon foam. By a further treatment stage of $2000^{\circ} \mathrm{C}$ and $2200^{\circ} \mathrm{C}$, the $\mathrm{D} / \mathrm{G}$ ratio decrease down to its minimum at 0.57 . As a result, the carbon structure has a high order in the formation of the graphitic layers and the healing process is completed. Contrary, several groups has been observed for CNTs a continuous reduction of the $\mathrm{D} / \mathrm{G}$ ratio with increasing of the treatment temperature $[26,28,29]$. For the determination of the crystalline width $\mathrm{L}_{\mathrm{a}}$, Knight and White developed the following empirical equation (3) [36].

$$
L_{a}=\frac{44}{I_{D} / I_{G}}
$$

Contrary to the increased $D / G$ ratio leads the thermal treatment to a reduction of the crystalline width, which begins to rise again at a transition point at $1880^{\circ} \mathrm{C}$ with increasing temperature.

Additionally, it should be mentioned that $\mathrm{G}^{\prime}$-peak is not split into a 2D-1 and a 2D-2 peak as known from graphite [37]. This is because of the number of layers (5-20 layers in Globugraphite) of the here presented carbon structure which has more common with few- layered graphene or multi-walled carbon nanotubes than with bulk graphite.

Additionally, to Raman spectroscopy and the determination of the crystalline width, BET technique can be used to analyse the graphitization progress in carbon structures, as present in Figure 3c. In summary, it should be noted, that the graphitization progress takes place in two key steps:

1. With beginning of the thermal treatment the carbon atoms start to reorientate themselves, which leads to an increase in the defect density and the specific surface area, as well as to a reduction of the crystalline width. Resulting of the reorientation the graphitic pieces are partial connected to larger graphitic areas.

2. By a further thermal treatment, the reorientation of carbon atoms is completed, which is resulting to a reduction of the $D / G$ ratio as well the surface area. Consequently the graphitic pieces are healed to graphitic layers, which is confirmed by a significantly increase in the crystalline width, a minimal D/G ratio and TEM observations.

The thermal annealing of the $3 \mathrm{D}$ carbon structures is an effective tool to improve and design the thermal and electrical properties of these materials. The graphitization of the several carbon pieces leads to large carbon layers, which was analyzed via TEM and Raman techniques. 

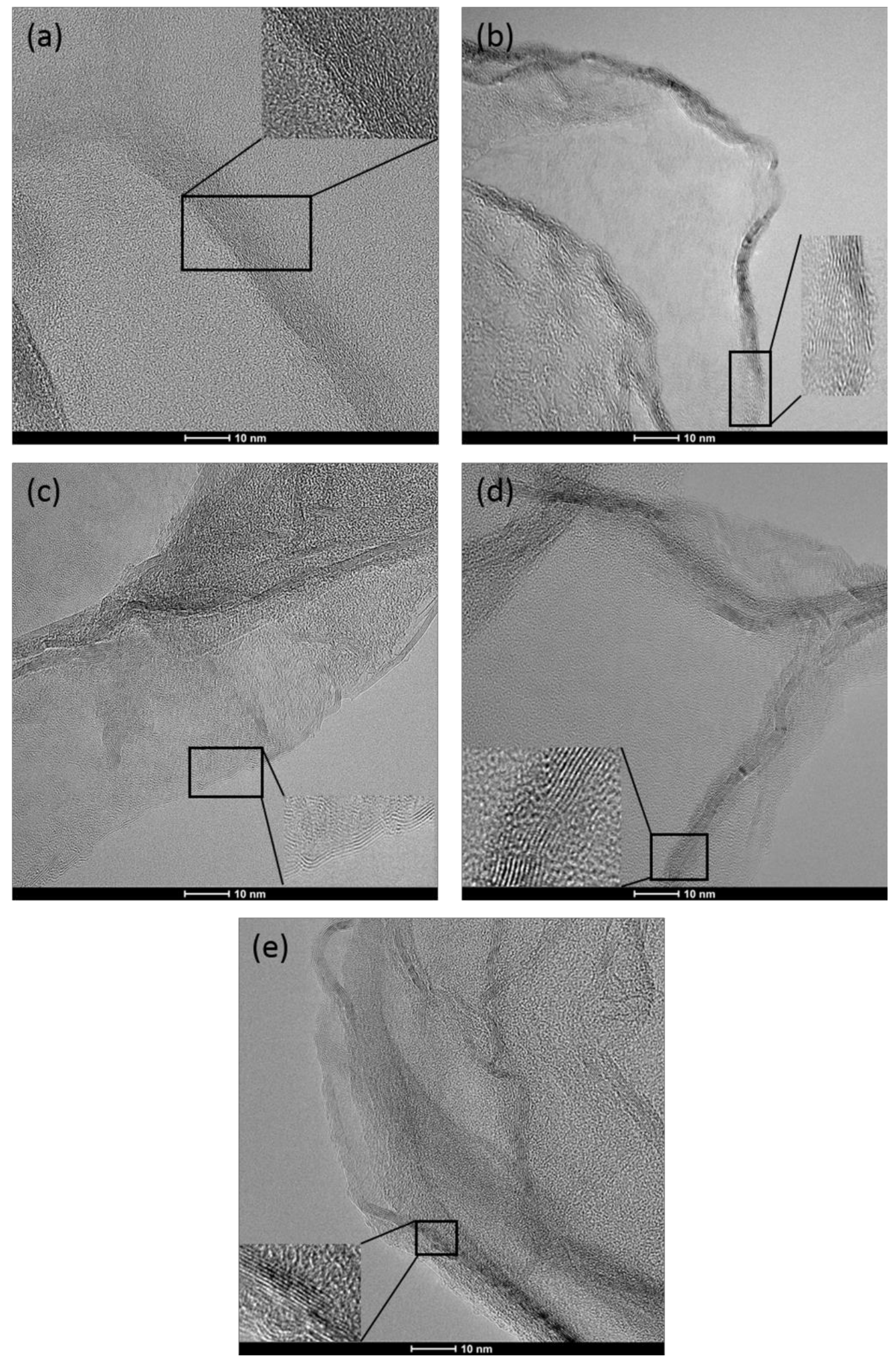

Figure 2. Dependency of the graphitization of the layers on the temperature: untreated (a), $1600^{\circ} \mathrm{C}(\mathrm{b}), 1800^{\circ} \mathrm{C}(\mathrm{c}), 2000^{\circ} \mathrm{C}(\mathrm{d}), 2200^{\circ} \mathrm{C}(\mathrm{e})$, the inserts have a scale bar of $5 \mathrm{~nm}$. 


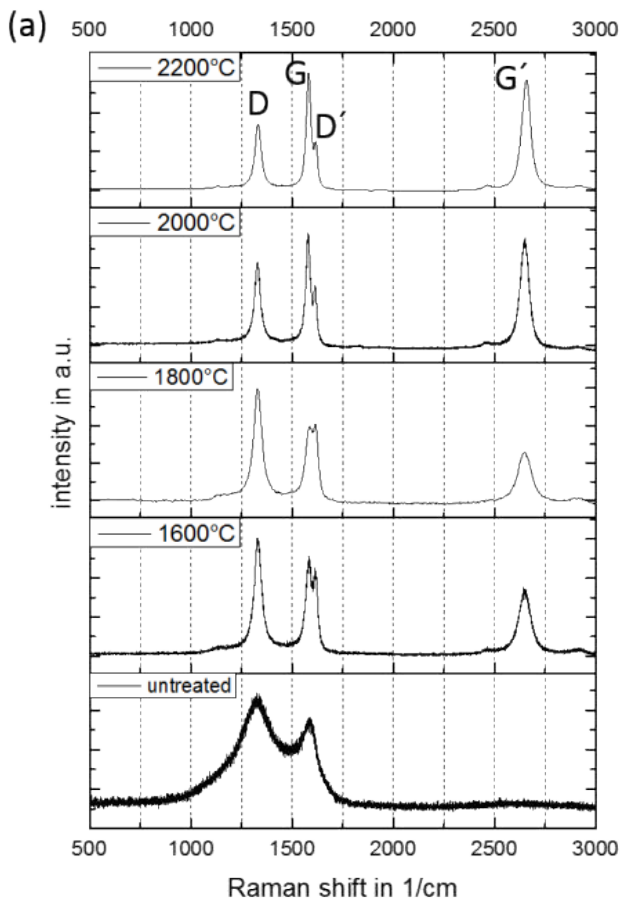

(b)

(c)
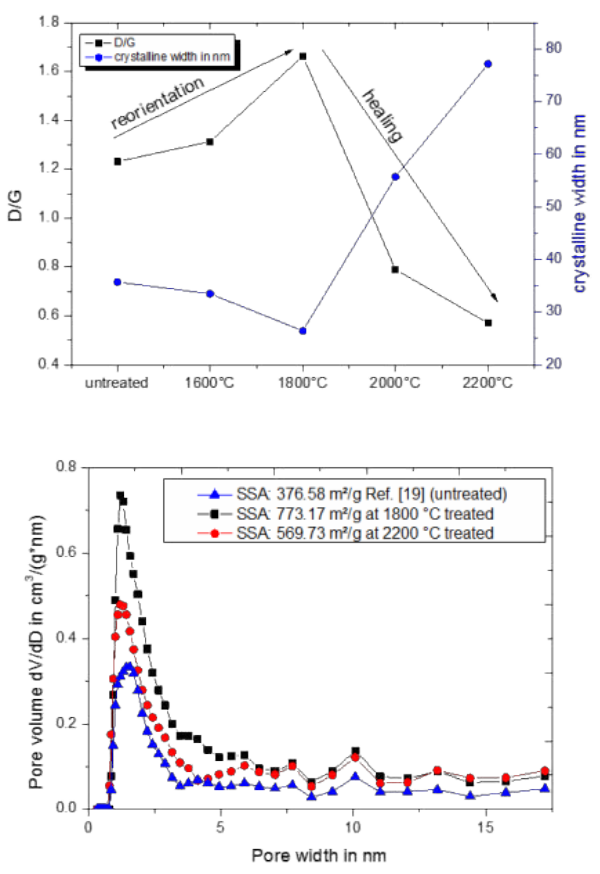

Figure 3. Raman spectra of the globular carbon structures in dependent of the annealing temperature (a), comparison of the $R\left(I_{D} / I_{G}\right)$ and the $D / G^{\prime}$ value of the annealed structures $(b)$ and a schematic model of the graphitization process (c).

The measurement of the electrical conductivity is an effective method to analyze the influence of the healing progress on the properties of these structures, as shown in Figure 4.

It shows, that with an increase in the electrical conductivity is associated with the treatment temperature. The untreated samples have an electrical conductivity of $7.7 \mathrm{~S} / \mathrm{m}$. The treatment increases the electrical conductivity from $9.4 \mathrm{~S} / \mathrm{m}$ up to $23.86 \mathrm{~S} / \mathrm{m}$ for temperature at $1600^{\circ} \mathrm{C}$ to $2200^{\circ} \mathrm{C}$. The significant increase of the electrical conductivity by annealing at $2200^{\circ} \mathrm{C}$ can be explained by the improved connection of the graphitic layers between the individual globular structures at the sintering necks to global connected graphitic layers which confirms the previously created model of the graphitization process based on the TEM and Raman observations. The formed $\mathrm{sp}^{2}$ lattices leads to a continiously increase of the electrical conductivity, notwithstanding a partial increase in defect density with the treatment temperature, is explained by an increase in the charge carrier density.

As a consequence of the observed phenomens an equation for the discribtion of the total electrical conductivity $\left(\sigma_{t o t}\right)$ is created, which is composed of the function of the conductive parths $f\left(\sigma_{c}\right)$ and the conductivity at the sintering necks $\sigma_{S N}(4)$.

$$
\begin{aligned}
& \sigma_{t o t}=f\left(\sigma_{c}\right)+\sigma_{S N} \\
& f\left(\sigma_{c}\right)=\sigma_{C C D}+\sigma_{D D}
\end{aligned}
$$

Where,

$$
\sigma_{\mathrm{CCD}}=\text { charge carrier density } \sigma_{\mathrm{DD}}=\text { defect density }
$$

Consequently, by the thernal treatment and the following key steps of the graphitization process, the reorientation and healing at the sintering necks is an essential parameter for the resulting electrical properties. The reorientation of carbon atoms, especially at the sintering

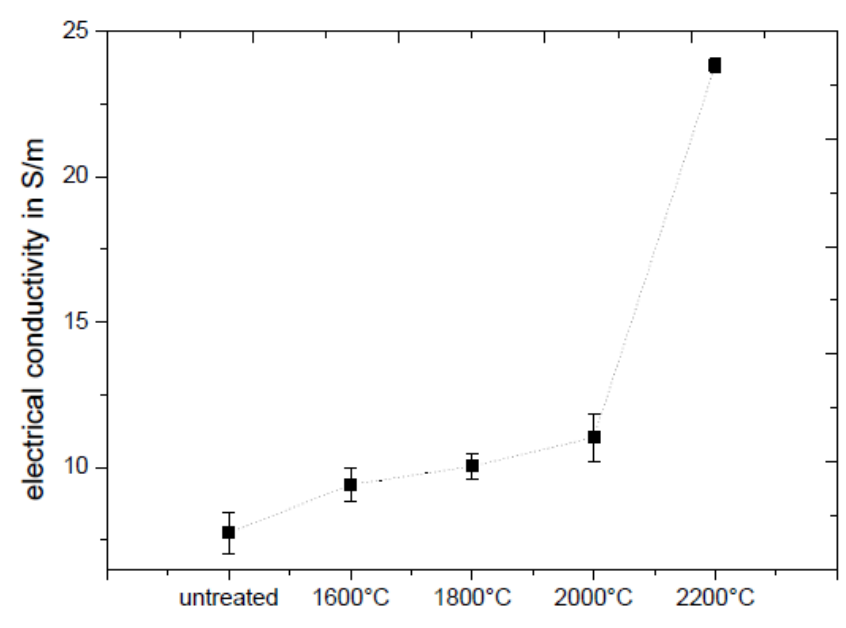

Figure 4. Dependency of the electrical conductivity of the treatment temperature.

necks leads to an increase in the D/G ratio and an higher amount of charge carrier, which is resulting in the improved conductivity. By the following healing, the sintering necks are formed to a high orientated graphitic interface, which explained the clear increase in the conductivity.

Additionally, the influence of the structural reorientation of the graphitic layers was investigated by using the TGA technique, as Figure 5 shows. Up to a temperature of $\sim 550^{\circ} \mathrm{C}$ for the untreated and $700^{\circ} \mathrm{C}$ for the treated carbon foam, the structure are stabil against the set temperatures. The improvement of the oxidation temperature can be explained by the healing and orientation into $\mathrm{sp}^{2}$ layers. The oxidation temperature could be increased from $700^{\circ} \mathrm{C}$ for the untreated carbon foam up to $\sim 770^{\circ} \mathrm{C}$ for the treated samples, which means an increase 


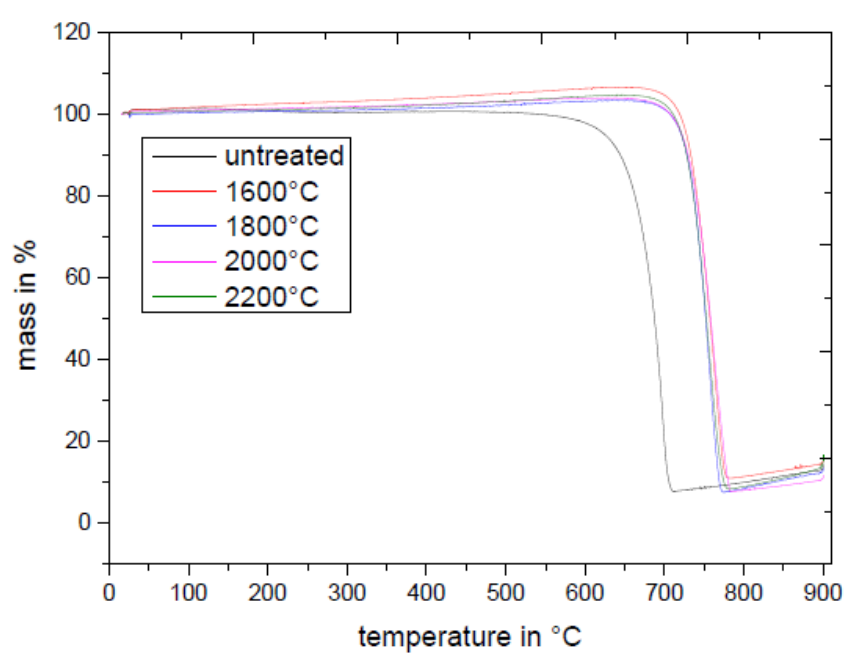

Figure 5. TGA spectra of the globular carbon structure dependent on the annealing temperature.

of $10 \%$. A further increase of the temperature treatment of more than $1600^{\circ} \mathrm{C}$ has no significant effect on temperature stability. So, that already $1600^{\circ} \mathrm{C}$ is enough to generate an optimal improvement. A further increase in the oxidation temperature with an increased treatment temperature doesn't leads to an improvement in the oxidation temperature. Due to the formation of $\mathrm{sp}^{2}$ hybridized carbon bonds (regardless of the treatment temperature), the resulting surface area is irrelevant relating to the oxidation temperature. The results from the measurements of the temperature stability are in good agreement with those of the TEM images and the Raman spectra. The mass increase from a temperature between $700^{\circ} \mathrm{C}$ for the untreated and respectively $800^{\circ} \mathrm{C}$ for the treated samples can be explained by the oxidation of the $\mathrm{Zn}$ residue to $\mathrm{ZnO}$.

\section{Conclusion}

In this study, a thermal treatment at $1600^{\circ} \mathrm{C}, 1800^{\circ} \mathrm{C}, 2000^{\circ} \mathrm{C}$ and $2200^{\circ} \mathrm{C}$ was used to improve the physical properties of $3 \mathrm{D}$ interconnected carbon foam with a hierarchical morphology. The thermal graphitization via a heat treatment of carbon foams is a powerful tool to heal structural defects on the atomic level. As a result, the graphitic pieces grow together and form graphitic layers, which is confirmed by the determination of TEM and Raman observations. Based on these analysis techniques, a structure-property equation for the discribtion of influences on the electrical conductivity was developed. The graphitization is carried out in two key steps, firstly the reorientation of carbon atoms followed by the healing of these crosslinkings and the connection of the sintered necks. This leads to the improved electrical conductivity and the low defect densities. Furthermore, it was shown that the analysis of Raman spectra is a simple but extremely effective tool to determine the healing process over the whole structure. Finally, the electrical conductivity increases with increasing temperature up to $300 \%$ and the oxidation temperature by $9 \%$.

\section{Acknowledgement}

JM gratefully acknowledge project funding by the German Research Foundation (DFG) SCHU 926/25-1 and HB, SG, BF acknowledge the European Union Seventh Framework Programme under grant agreement $n^{\circ} 604391$ Graphene Flagship. Additionally, the authors would like to acknowledge Mr. Manfred Geerken (Advanced
Ceramics, TUHH) and Mr. Robert Albrecht (FG Metallische und Verbundwerkstoffe, TU Ilmenau) for the thermal annealing of the samples. Moreover, we would like to acknowldge Mr. Mark Busch for the BET measurements.

\section{References}

1. Radushkevich L, Lukyanovich V (1952) About the structure of carbon formed by thermal decomposition of carbon monoxide on iron substrate. Zurn Fisic Chim 26: 88-95.

2. Geim AK, Novoselov KS (2007) The rise of graphene. Nat Mater 6: 183-191. [Crossref]

3. Karimov KS, Abid M, Saleem M, Akhmedov KM, Bashir MM, et al. (2014) Temperature gradient sensor based on CNT composite. Physica B 446: 39-42.

4. Hussain MA, Maqbool A, Khalid FA, Bakhsh N, Hussain A, et al. (2014) Mechanical properties of CNT reinforced hybrid functionally graded materials for bioimplants. Trans Nonferrous Met Soc China 24: 90-98

5. Allaoui A, Bai A, Cheng HM, Bai JB (2002) Mechanical and electrical properties of a MWNT/epoxy composite. Compos Sci Technol 62: 1993-1998.

6. Thostenson ET, Chou TW (2003) On the elastic properties of carbon nanotube-based composites: modelling and characterization. J Phys D: Appl Phys 36: 573-582.

7. Liao J, Tan MJ (2011) A simple approach to prepare Al/CNT composite: SpreadDispersion (SD) method. Materials Letters 65: 2742-2744.

8. Yang S, Huang G, Hua S, Hou X, Huang Y, et al. (2014) Improved electro chemical performance of the $\mathrm{Li} 1.2 \mathrm{Ni} 0.13 \mathrm{Co} 0.13 \mathrm{Mn} 0.54 \mathrm{O} 2$ wired by CNT networks for lithiumion batteries. Materials Letters 118: 8-11.

9. Chen Z, Ren W, Gao L, Bilu L, Songfeng P, et al. (2011) Three-dimensional flexible and conductive interconnected graphene networks grown by chemical vapour deposition. Nat Mater 10: 424-428. [Crossref]

10. Dong X, Cao Y, Wang J, Chan-Park MB, Wang L, et al. (2012) Hybrid structure of zinc oxide nanorods and three dimensional graphene foam for supercapacitor and electrochemical sensor applications. RSC Adv 2: 4364-4369.

11. Mecklenburg M, Schuchardt A, Mishra YK, Kaps S, Adelung R, et al. (2012) Aerographite: ultra lightweight, flexible nanowall, carbon microtube material with outstanding mechanical performance. Adv Mater 24: 3486-3490. [Crossref]

12. Gui X, Wei J, Wang K, Cao A, Zhu H (2010) Carbon Nanotube Sponges. Adv Mater 22: 617-621. [Crossref]

13. Liang HW, Guan QF, Chen LF, Zhu Z, Zhang WJ, et al. (2012) Macroscopic-Scale Template Synthesis of Robust Carbonaceous Nanofiber Hydrogels and Aerogels and Their Applications. Angew Chem Int Ed Engl 51: 5101-5105. [Crossref]

14. Zhang X, Sui Z, Xu B, Yue S, Luo Y, et al. (2011) Mechanically strong and highly conductive graphene aerogel and its use as electrodes for electrochemical power sources. J Mater Chem 21: 6494-6497.

15. Qiu L, Liu JZ, Chang SLY, Wu Y, Li D (2012) Biomimetic superelastic graphenebased cellular monoliths. Nat Commun 3: 1241. [Crossref]

16. Song B, Wu Z, Zhu Y, Moon K, Wong CP (2015) Highly Conductive Polyurethane/ Polyaniline-Based Composites for Wearable Electronic Applications. ECTC.

17. Marx J, Lewke MRD, Smazna D, Mishra YK, Adelung R, et al., (2017) Growth model of the 3D interconnected carbon structure "Aerographite" via ex-situ analysis, submitted to Applied Materials Today.

18. Parlak O, Mishra YK, Grigoriev A, Mecklenburg M, Luo W, et al., (2017) Hierarchical Aerographite nano-microtubular tetrapodal networks based electrodes as lightweight supercapacitor. Nano Energy 34: 570-577.

19. Marx J, Garlof S, Beisch H, Shvets RY, Grygorchak II, et al. (2017) Bio-inspired hierarchical electrodes for energy storage made by carbon replica process, in preparation.

20. Lupan O, Postica V, Mecklenburg M, Schulte K, Mishra YK, et al. (2016) Low powered, tunable and ultra-light aerographite sensor for climate relevant gas monitoring. J Mater Chem A 4: 16723-16730.

21. Lupan O, Postica V, Marx J, Mecklenburg M, Mishra YK, et al. (2017) Individual hollow and mesoporous aero-graphitic microtube based devices for gas sensing applications. Applied Physics Letters 110: 263109.

22. Sammalkorpi M, Krasheninnikov A, Kuronen A, Nordlund K, Kaski K (2004) Mechanical properties of carbon nanotubes with vacancies and related defects. Physical Review B 70: 245416. 
23. Rafiee R, Pourazizil R (2014) Evaluating the influence of defects on the Young's modulus of carbon nanotubes using stochastic modeling. Materials Research 17: 758-766.

24. Ishiyama U, Cuong NT, Okada S (2015) Influence of defects on carrier injection in carbon nanotubes with defects. Japanese Journal of Applied Physics 54: 065101.

25. Kim YA, Hayashi T, Osawa K, Dresselhaus MS, Endo M (2003) Annealing effect on disordered multi-wall carbon nanotubes. Chemical Physics Letters 380: 319-324.

26. Castillejos E, Bachiller-Baeza B, Pérez-Cadenas M, Gallegos-Suarez E, RodríguezRamos I, et al. (2012) Structural and surface modifications of carbon nanotubes when submitted to high temperature annealing treatments. Journal of Alloys and Compounds 536: $460-463$.

27. Jia K, Su Y, Chen Y, Luo J, Yang J, et al. (2015) Effects of defects and therma treatment on the properties of graphene. Vacuum 116: 90-95.

28. Behler K, Osswald S, Ye H, Dimovski S, Gogotsi Y (2006) Effect of thermal treatment on the structure of multi-walled carbon nanotubes. J Nanopart Res 8: 615-625.

29. Zhao J, Zhang Y, Su Y, Huang X, Wei L, et al. (2012) Structural improvement of CVD multi-walled carbon nanotubes by a rapid annealing process. Diam Relat Mater 25: 24-28.

30. Dresselhaus MS, Dresselhaus G, Saito R, Jorio A (2005) Raman spectroscopy of carbon nanotubes. Physics Reports 409: 47-99.
31. Dresselhaus MS, Jorio A, Saito R (2010) Characterizing Graphene, Graphite, and Carbon Nanotubes by Raman Spectroscopy. Annu Rev Condens Matter Phys 1: 89-108.

32. Beams R, Cancado LG, Novotny L (2015) Raman characterization of defects and dopants in graphene. J Phys Condens Matter 27: 83002.

33. Chandrasekaran S, Liebig W, Mecklenburg M, Fiedler B, Smazna D, et al. (2016) Fracture, failure and compression behaviour of a 3D interconnected carbon aerogel (Aerographite) epoxy composite. Compos Sci Technol 122: 50-58.

34. Garlof S, Mecklenburg M, Smazna D, Mishra YK, Adelung R, et al. (2017) 3D carbon networks and their polymer composites: Fabrication and electromechanical investigations of neat Aerographite and Aerographite-based PNCs under compressive load. Carbon 111: 103-112

35. Ferrari AC (2007) Raman spectroscopy of graphene and graphite: Disorder, electronphonon coupling, doping and nonadiabatic effects. Solid State Commun 143: 47- 57.

36. Knight DS, White WB (1989) Characterization of diamond films by Raman spectroscopy. J Mater Res 2: 385-393.

37. Ferrari AC, Meyer JC, Scardaci V, Casiraghi C, Lazzeri M, et al. 2006. Raman Spectrum of Graphene and Graphene Layers. Phys Rev Lett 97: 187401. [Crossref]

Copyright: (C2017 Marx J. This is an open-access article distributed under the terms of the Creative Commons Attribution License, which permits unrestricted use, distribution, and reproduction in any medium, provided the original author and source are credited. 